Proceedings of ASME 2013 International Design Engineering Technical Conferences \&

Design Theory and Methodology

August 4-7, 2013, Portland, OR, USA

IDETC2013/DTM-13087

\title{
VISUAL INSPECTION OR PRODUCT DISSECTION? THE IMPACT OF DESIGNER- PRODUCT INTERACTIONS ON ENGINEERING DESIGN CREATIVITY
}

\author{
Christine A. Toh \\ Department of Mechanical and Nuclear \\ Engineering \\ The Pennsylvania State University \\ State College, Pennsylvania, 16802 \\ Email: christinetoh@psu.edu
}

\author{
Scarlett R. Miller \\ School of Engineering Design, Technology and \\ Professional Programs \\ The Pennsylvania State University \\ State College, Pennsylvania, 16802 \\ Email:shm13@psu.edu
}

\begin{abstract}
Designers commonly interact with products in the early phases of design in order to understand the solution space and gain inspiration for new designs. Although designer-product interaction methods such as visual inspection and product dissection are recognized as a pivotal component of the engineering design process, little data is available on how these practices affect idea generation or when these activities are most useful for inspiring creative thought. Therefore, the current study was developed to understand the impact of these activities on creative idea generation. During our controlled study, fifty-nine undergraduate engineering students were instructed to either visually inspect or physically dissect an example milk frother and then generate ideas for a new, innovative design. These concepts were then evaluated for their novelty, variety, quality and quantity. Our analysis (ANOVA) revealed that participants who physically dissected the example frother produced ideas that were more novel but of lower quality than those that simply inspected the frother. Our results provide insights on the impact of designer-product interactions on creativity and we use these findings to develop recommendations for the use and alterations of these practices for improving creativity in engineering design.
\end{abstract}

Keywords: design creativity; product dissection; design activity; visual inspection, product-designer interaction.

\section{INTRODUCTION}

Designers often interact with existing products in the early phases of design in order to understand the solution space and gain inspiration for new ideas [1]. These interactions can vary from visually inspecting the product to physically dissecting the product in an effort to gain an understanding of the innerworkings of the design. These designer-product interactions are a vital part of the design process because new designs are often derivations or variations of existing products [2]. Therefore, these product interactions serve to aid designers in identifying components of existing products that can be re-used or recombined to form new design ideas.

Although the use of example products in the early phases of design is pervasive in engineering, research in this space has focused primarily on developing formalized ideation methods (eg. SCAMPER and TRIZ) or understanding how carefully selected 2D examples impact creativity. This is problematic because formalized methods are not commonly adopted in design practice due to the perception that these methods are burdensome and thus, detract from the creative process [3]. In addition, while most designers utilize $3 \mathrm{D}$ representations (e.g. models) during the design process, most research in this space has focused on the impact of the designer's interactions with 2D (e.g. pictorial) representations. Therefore, research is needed that studies the effects of physical (3D) designerproduct interactions in order to understand their impact on design creativity. This knowledge would allow us to understand the most appropriate use of these practices during the design process.

Researchers have started to explore the importance and utility of working with 3D models during idea generation. For instance, Viswanathan and Linsey (2010) studied the impact of building physical models, as opposed to sketching 2D images, during idea generation [4]. They found that while developing $3 \mathrm{D}$ prototypes can help facilitate better visual representations of the ideas, they might limit the originality of the generated concept. Other studies $[5,6]$ aimed at understanding the impact 
of product dissection (3D) found that participants who interacted with existing products by dissecting them into their sub-components prior to idea generation not only developed more ideas, but developed ideas that were more novel than those that did not dissect the product. Although these studies provide insights into the potential utility of product dissection and 3D interactions, they did not compare this method to other $3 \mathrm{D}$ product interactions such as visually inspecting the product. Therefore, while this research recognizes the importance of $3 \mathrm{D}$ product interactions on design creativity, it is unclear how the type of interaction a designer has with a $3 \mathrm{D}$ representation affects design creativity.

The current study was developed to provide insights into the impact of two commonly used 3D designer-product interaction techniques, product dissection and visual inspection, on the creativity of design outcomes. This was accomplished by conducting a controlled study with first-year engineering students. The results from this study can be used to gain insights into the impact and utility of these two designerproduct interactions. In addition, this research highlights the need to examine the impact of existing design practices in order to develop more effective design methods for inspiring design creativity.

\section{Designer-Product Interactions}

Prior to generating design solutions, designers typically interact with existing products to gain inspiration and understand the solution space [7]. In other words, interactions with existing products play an important role in orienting the designer to the goals of the design problem and provide designers with insight on the inner-workings of competitors' products. In a sense, designers use examples to gain inspiration and 'jump start' the creative process. These designer-product interactions can take occur in many forms, ranging from visually inspecting the product to physically dissecting the product. Since these interactions occur early on in the design process, the type of interaction the designer has with the product has the potential to impact the subsequent development of innovative design ideas.

Visual inspection is a commonly used interaction method that includes the designer visually inspects the product to gain an understanding of its physical structure. This process often involves benchmarking activities where the product is assessed for its quality or aesthetics, as well as other information capturing practices such as sketching the product [8]. Visual inspection is considered a surface-level interaction because it does not aid the designer in uncovering the internal structure or inner-workings of the analyzed product.

Product dissection, on the other hand, is considered a deeper interaction method because it involves systematically taking apart products into their components (including the mechanical components) to uncover opportunities for re-design [6]. It is recognized as a beneficial activity in both industry and academia, and occurs in the early stages of design, typically after the design goal has been established, as a supplement or replacement for visual inspection. At the industry level, companies perform product dissection to provide competitive benchmarks and gain knowledge and insights into a particular product. At the educational level, product dissection provides students insight into industry practice [9] and 'hands-on' experience [10]. Importantly, studies have shown that teambased product dissection can reduce fixation effects [11] and increase design novelty [5]. However, the differences between the surface-level physical interactions with the product and the dissection of the product have remained largely unexplored in the literature. One study on this topic has shown that students that perform product dissection in a team environment are more creative, develop more ideas, and explore both the form and function of a design compared to those that simply interacted with the product [6]. This has important implications because it suggests that the type of designer-product interaction may play an important role in the creativity of design outcomes.

While the literature lacks information on the difference between product dissection and surface-level physical interactions, other studies have explored the impact of other forms of physical interaction on the design process. Researchers have found that even though physical interactions such as 3D prototyping can help facilitate a better visual representations of the product, it can also limit the originality of the generated ideas $[12,13]$. This is due to the fact that physical models often limit the scope of the explored solution space by acting as a constraining example. In contrast, dissection provides a deeper understanding of the product and encourages designers to consider previously-ignored aspects of the product which is ultimately the goal of other ideation techniques that seek to increase design creativity [14, 15]. From a cognitive standpoint, the depth of information gained from dissection activities may serve to provide cognitive stimulation to designers [16]. In fact, research regarding cognitive stimulation in idea generation has shown that relevant information from examples can activate concepts in long-term memory. These concepts are typically related semantically to form a representation of the knowledge structure regarding a particular domain, or as it is commonly referred to in the cognition literature, a semantic network [17]. Therefore, the rich stimulation provided by dissection activities may lead to an associational chain of ideas that serve to increase design novelty [18].

While many studies have highlighted the utility of designer-product interactions, few research studies focused on how these interactions impact the creativity of design outcomes. This is important because product dissection and visual inspection are frequently used in industry and in engineering education $[9,19,20]$ and thus, can provide insights on how to develop practical creativity-increasing methods. Therefore, this study was developed to respond to this research gap. 


\section{The Impact of Example Dimensionality on Design Creativity}

While research should focus on understanding the impact of existing designer-product interactions on creativity, it is also important that we identify the importance of the type of example used for inspiration. In particular, understanding the impact of 2D versus 3D examples is important because both types of examples play an important role in the design process.

Research regarding the use of $2 \mathrm{D}$ examples in engineering design is plentiful. In particular, research in this area has focused on understanding the impact of carefully selected 2D pictorial examples on design creativity. Studies have shown that these 2D examples can negatively impact idea generation by fixating designers on features found within the example set, thereby reducing the creativity of design outcomes. This limiting adherence to existing examples is termed design fixation [12] and has been shown to affect different levels of expertise [15] and different design disciplines [13]. Therefore, researchers have focused on developing methods that support the example-centric design process by expanding the solution space in the early stages of design. For instance, research in this area has shown that it is possible to increase design creativity by providing participants with specific instructions [14] or by providing useful analogies [15]. Other studies have looked at creativity-increasing techniques used in engineering design such as TRIZ [21], SCAMPER [22], Brainstorming [23], Brainsketching [24], C-sketch [25], and Gallery [24] techniques.

While 2D examples are often studied in the engineering literature for their impact on creativity, 3D examples (models, products) are often used in academia and industry to help designers benchmark on competing products and develop ideas. It is also important to study the dimensionality of examples and their utility in design practice because research on visuo-spatial representation in learning and retention have suggested that 3dimensional models have the ability to improve understanding and comprehension compared to static, 2-dimensional models $[26,27]$. This is due to the richer and more diverse store of spatial representations acquired by the individual when viewing objects in the 3-dimensional space [28]. As a result, researchers have argued that this richer mental representation of the object allows for easier retrieval of information and the application of knowledge [29] and thus, can positively impact creativity.

The impact of example dimensionality has received little attention in the field of engineering design beyond the exploration of textual and visual-based examples [30]. However, recent studies have begun to address the impact of example dimensionality on design creativity. For instance, Viswanathan and Linsey [31] explored the impact of 2D pictorial examples and 3D physical examples and found that physical examples encouraged the generation of more ideas compared to the pictorial examples [31]. Another study, while not directly investigating the impact of example dimensionality, found that interacting with physical prototypes significantly reduced the number of features reused during idea generation
[32]. In addition, researchers such as Viswanathan et al. [33] have also shown that students that build physical prototypes of their ideas fixate less on the negative features of the example design. Thus, it becomes clear that 3D examples are powerful in shaping design cognition and consequently, design outcomes.

This research thread is particularly relevant to the study of increasing design creativity in situ because they examine the use of currently practiced design methods, such as interacting with physical examples and prototyping. Furthermore, because physical examples are 3-dimensional in nature, the degree of detail and interaction is significantly different from 2dimensional examples. Namely, viewing objects in the 3dimensional space allows for a richer and more diverse store of spatial information acquired by the designer [28], resulting in easier retrieval of information [29]. However, most studies in this space have focused on the impact of building and interacting with prototypes, rather than the effects of interacting with commercially available products. This is important because designers often examine and interact with existing products in the earlier stages in order to gain knowledge and insights into the design problem [9]. One such activity that involves examining and taking apart existing products is product dissection. Product dissection is particularly apt for increasing creativity as it can be implemented without specificity to the problem and it has previously been shown as a beneficial activity in the engineering design setting $[9,19,20]$. Therefore, this study responds to this research gap by examining the role of product dissection on design creativity.

\section{Research Objectives}

The purpose of this study is to examine the impact of two commonly used designer-product interactions (product dissection and visual inspection) on design creativity. In particular, this study aims to answer the following research questions:

Question 1: Is the novelty of the generated designs impacted by the method of interaction with the example (visual inspection or product dissection)? We hypothesize that design novelty will increase due to exposure to a product dissection activity compared to the visual inspection activity since prior research has shown a positive relationship between participation in dissection activities and design novelty [5].

Question 2: Is the variety of the generated designs affected by the type of interaction with the example? Our hypothesis is that performing the dissection activity will increase design variety compared to visual inspection since researchers have argued that dissection has the potential to expose designers to previously unknown aspects of the design that serves to inspire creativity through self-discovery [34]. 
Question 3: Does performing the dissection activity increase the number of ideas generated? We hypothesize that the quantity of ideas produced will be increased due to participation in the product dissection activity over the visual inspection activity since researchers have shown a positive correlation between the number of ideas generated and dissection in exploratory studies [6].

Question 4: Does participation in the dissection activity impact design quality compared to visual inspection? Our hypothesis is that product dissection will increase design quality since dissection allows designers to gain a better understanding of the product's working principles and encourages more focus on the functional aspects of design [35].

Design creativity was analyzed using these four categories (novelty, quality, variety and quantity) in order to identify the impact that these types of designer-product interactions have on specific facets of design creativity. This multi-faceted approach was chosen over other single-metric assessments, such as those developed by Nelson et al. [36], in order enable a more comprehensive interpretation of the creativity results.

\section{METHODOLOGY}

To answer these research questions, a controlled study was conducted with 59 undergraduate engineering students. This section serves to summarize the methodological approach taken in this study.

\section{Participants}

Participants were recruited from 10 sections of a first-year undergraduate engineering design course at a large northeastern university. Extra credit in the course was provided as compensation for participation in the study. In all, 59 students (34 males, 25 females) between the ages of 18 and 21 (mean of 18.3) participated in the study.

\section{Procedure}

Prior to the start of the study, each participant was blindly assigned to either the visual inspection or product dissection condition. Participants in each group performed their assigned activity at the same time and location as their group members.

At the start of the study, the purpose and procedure of the study were discussed and any questions were answered. Next, participants completed an informed consent document and were provided with the following problem description:

"Your task is to develop concepts for a new, innovative, product that can froth milk in a short amount of time. This product should be able to be used by the consumer with minimal instruction. Focus on developing ideas relating to both the form and function of the product."
Once the description was read, participants were given 20 minutes to complete either a visual inspection $(\mathrm{N}=29)$ or a product dissection $(\mathrm{N}=30)$ of an IKEA milk frother (article number 100.763.20), see Figure 2.
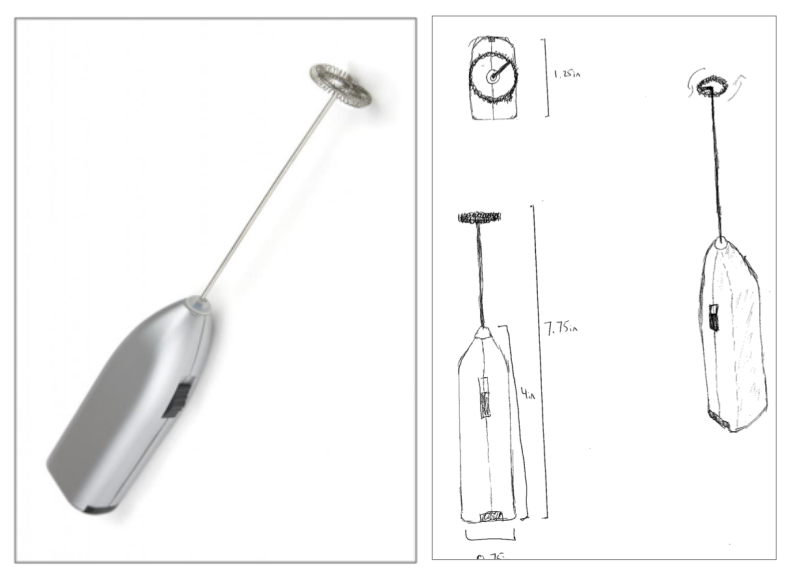

Figure 2: EXAMPLE MILK FROTHER USED IN THE STUDY (LEFT) AND SKETCH OF THE MILK FROTHER BY PARTICIPANT 57 (RIGHT).

In the visual inspection condition, participants were instructed to sketch the front, top and side view of the product and provide dimensions on the drawings, as is commonly done in engineering practice [8]. An example of an engineering drawing utilizing these views was presented to participants to guide them in this activity. Participants were also asked to complete a benchmarking activity where they were asked to rate the milk frother based on its aesthetics, functionality, durability, and ease of use, see Figure 2. This activity was modeled after typical engineering practice, where designers often systematically assess existing examples in order to gain information on competitor's products [8].

In the dissection condition, participants were asked to identify each of the 12 component parts of the example frother and complete a bill of materials for each component, as it is typically done following dissection in engineering design [37]. They were also asked to create a functional layout diagram where they laid out each of the 12 parts, described the function of each part and described its connectivity with the other components on a single sheet of paper, see Figure 3. This activity was developed in order to simulate the construction of an exploded view, an activity typically done in conjunction with dissection to enhance understanding [35], but utilizing the actual components of the dissected product. The instructions as well as worksheet for these activities can be found in the Appendix. 


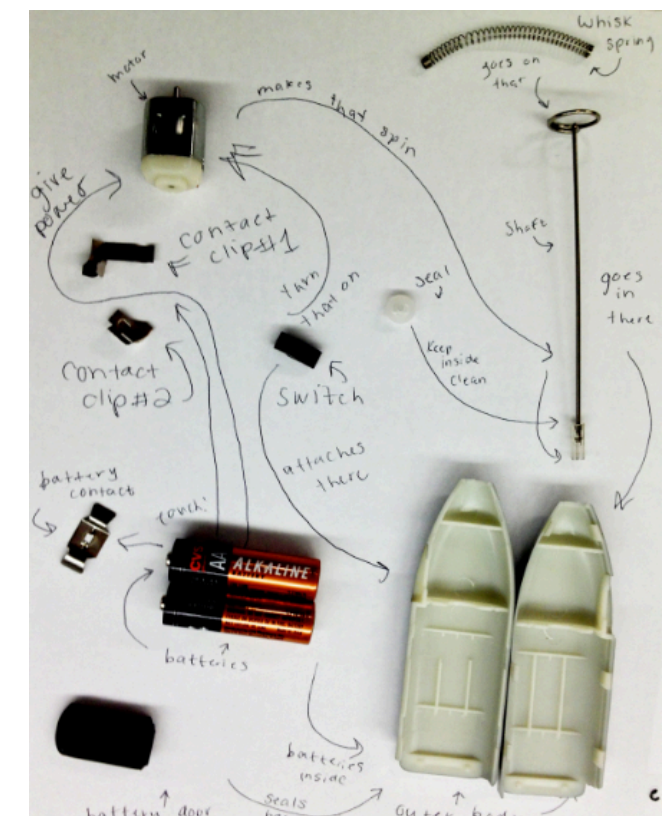

Figure 3: A MILK FROTHER DISSECTED BY PARTICIPANT 54.

Once participants completed the visual inspection or dissection activity they were provided with numbered sheets of papers and given 20 minutes to sketch as many concepts as possible for a novel milk frother. They were asked to put only one idea on each sheet of paper and write notes on each sketch such that an outsider would be able to understand the concepts upon isolated inspection, see Figure 4. At the conclusion of the study, participants were informed that they were not allowed to discuss the study with others for a period of one week following their participation.

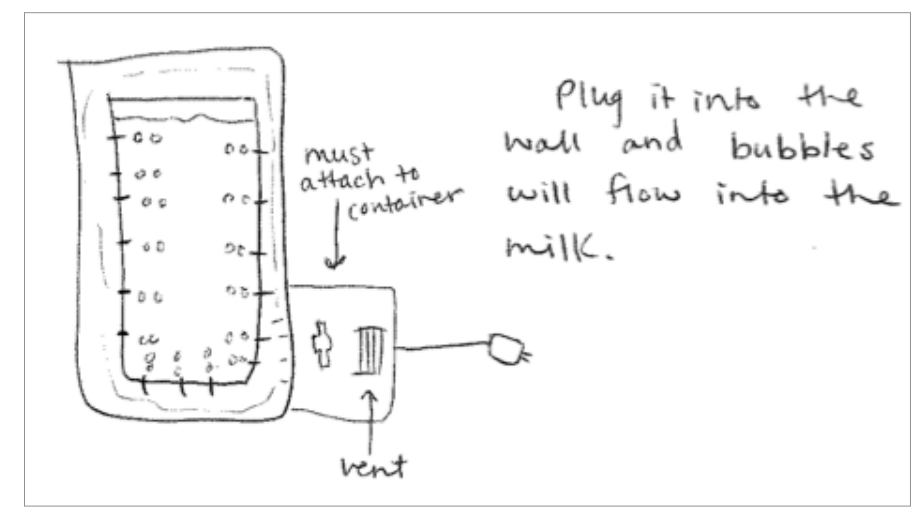

Figure 4: EXAMPLE BRAINSTORMING SKETCH BY PARTICIPANT 32.

\section{Metrics}

In order to investigate the creativity of the concepts generated, the four creativity metrics developed by Shah et al. [38] were utilized which include calculations for the novelty, quality, variety and quantity of the designs generated. This multi-faceted assessment method was chosen over other singlemetric assessments, such as those developed by Nelson et al. [36], in order to identify the specific differences of the two designer-product interactions in terms of engineering creativity.

The creativity metrics developed by Shah et al. utilize a feature tree approach that categorizes each design based on the features that it addresses. Therefore, in order to quantify the concepts generated during the study in terms of the four creativity metrics, the following process was used to identify and classify the features each concept addressed: (1) In order to calculate the novelty and variety of these designs, twenty coding questions were developed by the researchers to classify the features that each concept addressed, see Figure 5 for example. These questions were derived from features of the original design, as well as the solution space explored by all participants in their designs, as was done in previous studies [5, 11]. (2) In order to identify the quality of each design concept, three questions were developed that asked raters to identify the about the technical feasibility of the idea, similar to the process used in [39]. (3) Finally, the quantity of concepts generated was computed by counting the total number of idea sheets completed by each participant in the brainstorming activity. These metrics and calculations are explained in detail in the following sections.

Once the questions were developed, two independent raters were recruited to classify and rate the design examples using the 23-question survey. Both raters were required to attend a training session on design example rating in order to improve inter-rater reliability, which is often low for the Shah et al. metrics (see Nelson et al. [36] and Srivathsavai et al. [40] for discussion). During the training session, the intent behind each of the 23 questions on the survey was discussed with both raters and the raters were required to practice rating example designs and discuss their rationale for their ratings with one another using the 23 question online survey, which was implemented using Qualitrics. Once the training was completed, the raters then utilized this same system to rate each of the 488 total ideas developed during this study.

The Cohen's Kappa (inter-rater reliability) was 0.80 for the 20 coding questions, and 0.98 for the 3 quality questions. As was done in previous studies investigating creativity [5, 11, 41], any disagreements in the answers for the rating questions were settled in conference between the two raters once all original ratings were complete.

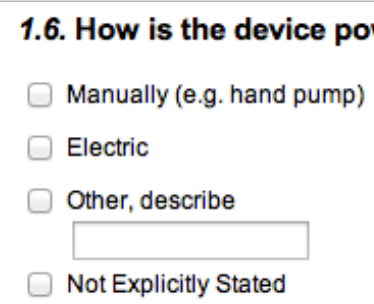

Figure 5: EXAMPLE CODING QUESTION USED TO IDENTIFY FEATURES OF THE GENERATED DESIGNS 
The 23 rating questions were used to indicate the features that each concept addressed and the quality of the overall design. This data was used to calculate the four creativity metrics for each participant in the following manner:

\section{Design Novelty}

Novelty is the "measure of how unusual or unexpected an idea is compared to other ideas" (p. 117) [38] and was calculated in this study according to Shah et al. [38]. In order to assess the amount of novelty in the designs generated by each participant, the novelty of each feature was calculated. This feature novelty is defined as the novelty of each feature, $i$, as it compares to all other features addressed by all the generated designs. Feature novelty, $f_{i}$, can then vary from 0 to 1 , with 1 indicating that the feature is very novel compared to other features. The method of computing $f$ is shown in Equation 1:

$$
f_{i}=\frac{T-C_{i}}{T}
$$

Where $\mathrm{T}$ is the total number of designs generated by all participants, and $\mathrm{C}$ is the total number of designs that were rated as being addressed by the design. The novelty of each design, $j$, is then determined by the combined effect of the Feature Novelty, $f_{i}$, of all the features that the design addresses. Because D is computed for all the features, the novelty per design is computed as a percentage out of the total possible design novelty, as seen in Equation 2.

$$
D_{j}=\frac{\sum f_{k}}{\sum f_{i}}
$$

Where $f_{k}$ is the feature novelty of a feature that was different from the original design, and $f_{i}$ is the feature novelty of a feature that was addressed in the generated idea (not rated as 'Not Explicitly Stated').

The novelty of each participant for the idea generation activity is then determined as the maximum design novelty, $\mathrm{D}_{\mathrm{j}}$ of all the designs each participant generated in each category. While average novelty has been more typically used in the literature [38, 42], maximum novelty is used in this study because it "measures the possibility of attaining a maximum novelty score" (p. 7), which is of more interest in this study than the novelty scores of all design ideas generated, novel or not. [43].

\section{Design Variety}

Variety is defined as a measure of the extent to which the solution space is explored during idea generation [38]. The variety metric was calculated by first computing the variety of each question that was addressed by the participant, similar to the method used by Shah et al. [38] in evaluating the variety of each function. This was done using Equation 3, where $b_{q}$ is the number of options addressed for question $\mathrm{q}$ by ALL of the participant's ideas, and $\mathrm{N}$ is the total number of ideas generated by Participant 1 .

$$
V_{q}=\frac{b_{q}}{N}
$$

The amount of variety produced by each participant's generated designs is then computed as the total variety of all questions, as seen in Equation 4, where $\mathrm{Q}$ is the total number of questions addressed by all designs generated by a participant.

$$
V_{T}=\sum_{q=1}^{Q} V_{q} / Q
$$

\section{Design Quality}

Quality is defined as a measure of a concept's feasibility and how well it meets the design specifications [38]. Similar to Linsey et al. [39], we measured quality on an anchored three point scale. The quality metric was calculated using the raters' answers to the final 3 questions on the 23-question survey, see Figure 6.

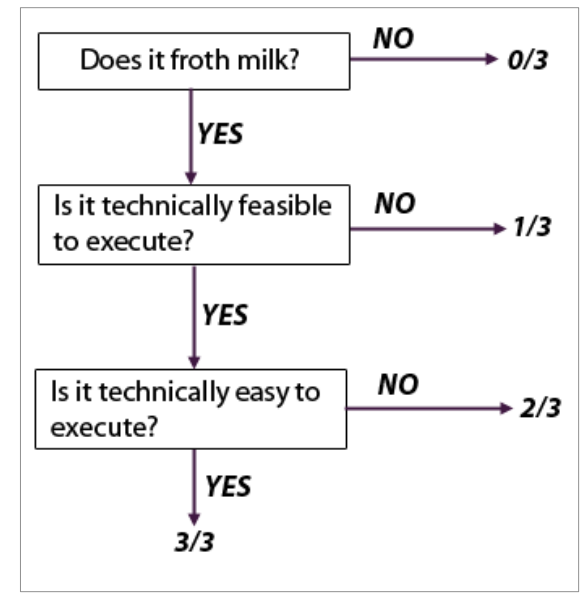

Figure 6: QUALITY SCORES ASSESSED USING THE 3POINT SCALE.

The first of these questions evaluated the degree to which the design addressed the design goal (i.e., to design a device that froths milk). The remaining questions evaluated the feasibility of the generated design. Specifically, the technical feasibility of the design (is it possible to make it) and the ease of execution (is it plausible to make it) were evaluated. The quality of each design was then computed using Eqn. 5, where $\mathrm{q}_{\mathrm{k}}$ is the answer to each of the quality questions. $\mathrm{q}_{\mathrm{k}}=1$ when the quality question is answered with a 'yes', and $\mathrm{q}_{\mathrm{k}}=0$ when the quality question is answered with a 'no'. The quality score for each participant is then obtained by computing the average quality scores of all designs that the participant generated.

$$
Q_{j}=\frac{\sum q_{k}}{3}
$$


Examples of designs that scored high and low on the quality metric are shown in Figure 7.

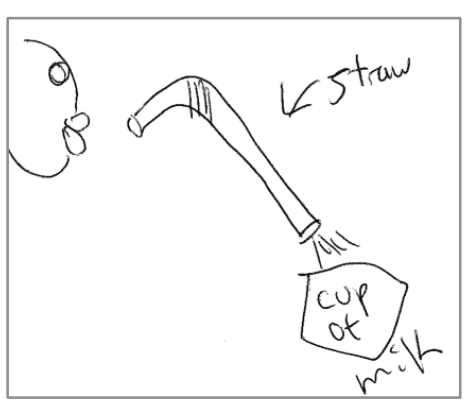

(a) Low quality (1/3)

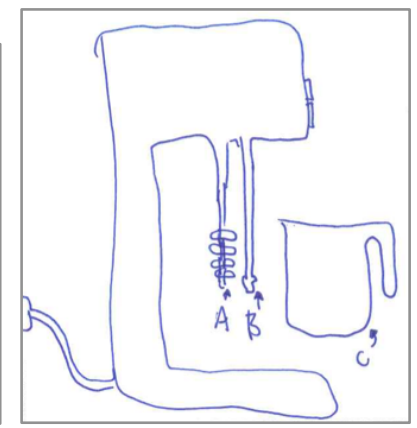

(b) High quality (3/3)
Figure 7: EXAMPLES OF DESIGNS WITH (A) LOW QUALITY THAT SCORED A 1/3, AND (B) HIGH QUALITY THAT SCORED A $3 / 3$.

\section{Idea Quantity}

The final creativity metric was the quantity of ideas developed. This was computed for each participant by counting the total number of idea sheets completed by each participant in the brainstorming activity. As stated previously, each participant was instructed to put only one idea per sheet of paper.

\section{RESULTS}

To test our hypotheses that design creativity is impacted by the type of designer-product interaction, statistical analyses (ANOVAs) were computed with the independent variable being the type of interaction with the product (visual inspection or product dissection) and the dependent variables being the four creativity metrics. SPSS v. 20 was used to analyze the findings and a significance level of 0.05 was used in all analyses. A summary of the results can be found in Table 1 .

\section{Table 1: ANOVA RESULTS WITH THE INDEPENDENT VARIABLE BEING THE TYPE OF DESIGNER- PRODUCT INTERACTION.}

\begin{tabular}{|l|c|c|c|c|c|}
\hline $\begin{array}{l}\text { Dependent } \\
\text { Variable }\end{array}$ & SS & DOF & MS & F $_{\mathbf{0}}$ & P-value \\
\hline Novelty & $\mathbf{0 . 0 3}$ & $\mathbf{1}$ & $\mathbf{0 . 0 3}$ & $\mathbf{4 . 0 7}$ & $\mathbf{0 . 0 5}$ \\
\hline Variety & 0.00 & 1 & 0.000 & 0.00 & 0.99 \\
\hline Quantity & 13.26 & 1 & 13.26 & 1.35 & 0.25 \\
\hline Quality & $\mathbf{0 . 0 3}$ & $\mathbf{1}$ & $\mathbf{0 . 0 3}$ & $\mathbf{5 . 4 2}$ & $\mathbf{0 . 0 2}$ \\
\hline
\end{tabular}

The following sections outline these results in relationship to our research hypotheses.

\section{Design Novelty}

Our first hypothesis was that participants who were involved in the product dissection activity would develop ideas that were more novel than those who only visually inspected the product. The ANOVA results revealed a significant relationship between design novelty and the type of interaction with the example product $\left(\mathrm{F}_{0}=4.07, \mathrm{p}<0.05\right)$ indicating that participants who performed the product dissection activity $(\mathrm{M}=$ $0.79, \mathrm{SD}=0.09$ ) generated ideas that were more novel compared to participants who participated in the visual inspection task $(\mathrm{M}=0.74, \mathrm{SD}=0.08)$. This finding indicates that ideas produced after product dissection were more novel than those produced after visual inspection, confirming our hypothesis. This result suggests that participants who dissected the product were able to generate ideas that were more unusual or unexpected [38] compared to participants who performed visual inspection as a result of being exposed to previously unexplored aspects of the product $[6,35]$.

\section{Design Variety}

Our second hypothesis was that participants who participated in the product dissection activity would produce a larger variety of ideas than those who only participated in the visual inspection activity. However, the ANOVA results indicate no significant difference in the variety of the designs generated between the two conditions $\left(\mathrm{F}_{0}=0.00, \mathrm{p}<0.99\right)$. Namely, the variety scores did not differ significantly between the visual inspection $(\mathrm{M}=0.26, \mathrm{SD}=0.07)$ and product dissection conditions $(\mathrm{M}=0.26,0.09)$. This result indicates that the type of designer-product interaction has no impact on the variety of the ideas generated during this study.

This finding contradicts prior studies that have argued that dissection exposes designers to unknown aspects of the design [34] and thus, can inspire creativity. However, these studies did not compare dissection with other forms of physical interaction. Thus, this result adds to our understanding of the impact of designer-product interaction on design creativity.

\section{Design Quantity}

Our third hypothesis was that participants who were involved in the dissection activity would produce more ideas than those that were not. Our ANOVA results did not reveal a significant difference in the number of ideas generated $\left(\mathrm{F}_{0}=\right.$ $1.35, \mathrm{p}<0.25)$ between the visual inspection condition $(\mathrm{M}=$ $8.45, \mathrm{SD}=3.65)$ and product dissection conditions $(\mathrm{M}=7.50$, $\mathrm{SD}=2.54)$. Thus, it can be concluded that the two types of interaction with the product had no impact on the number of ideas developed. This finding differs from the results of a previous study that states that product dissection has the ability to encourage the generation of more ideas when compared with 
physical interactions without dissection [6]. However, in this previous study, participants were not instructed to perform benchmarking and sketching activities in the physical interaction condition, suggesting that these types of activities may impact ideation fluency.

\section{Design Quality}

Our final hypothesis was that participants who were involved in the product dissection activity would produce higher quality ideas than those that performed the visual inspection activity. The ANOVA results revealed that design quality was significantly affected by differences in designproduct interactions $\left(\mathrm{F}_{0}=5.42, \mathrm{p}<0.02\right)$. Specifically, the results show that participants who performed the visual inspection activity $(\mathrm{M}=0.97, \mathrm{SD}=0.05)$ generated higher quality concepts than participants who performed the product dissection activity $(\mathrm{M}=0.92, \mathrm{SD}=0.09)$, refuting our hypothesis. This finding adds new knowledge to the literature on product dissection that states that dissection allows designers to gain a better understanding of the product's working principles and encourages more focus on the functional aspects of design [35].

\section{DISCUSSION}

The main goal of this study was to investigate the differences in design outcomes between two different types of designer-product interactions. Our results showed that individuals who participated in product dissection produced ideas that were more novel, but had lower quality than those that performed the visual inspection task. This result has implications for engineering design because researchers have long since considered successful creative design to be a combination of the novelty and quality measures of the final design [38, 44]. From our results and exploring the related literature, several themes and implications for design cognition and practice emerged that are discussed in detail below.

\section{Designer-Product Interactions Matter}

The main finding of this research is that the type of interaction a designer has with a product in the early phases of design influences specific facets of creativity, namely the novelty and quality of the generated designs. In fact, our study found that while product dissection encouraged design novelty, it had a negative impact on design quality compared to visual inspection. There are several important implications for this finding.

First, our results revealed that product dissection supports novel idea development over visual inspection methods, indicating that a more in-depth examination of the product (over more superficial interactions) can inspire novel directions during idea generation. Thus, dissection can be seen as a useful tool in early phase conceptual design when designers are trying to explore previously unknown areas of the solution space in order to increase the likelihood of generating innovative ideas. The more detailed nature of product dissection may provide more cognitive stimulation to designers [16], activating concepts in long-term memory that are connected through a semantic network [17]. Therefore, the rich stimulation provided by dissection activities lead to an associational chain of ideas that serve to increase design novelty [18].

Second, the results of the study showed that participants that performed the visual inspection generated higher quality ideas compared to participants that performed product dissection. Therefore, visual inspection should be seen as the preferred product-interaction method over product dissection when designers need to focus their design ideas or improve the quality of the product. This result could be attributed to the fact that participants that performed dissection were more exposed to the internal mechanisms of the product, inspiring more focus on these functional aspects during idea generation. However, studies have found that product dissection serves to encourage the application of existing knowledge to a problem [45]. Thus, it is possible that the participants that performed product dissection focused on modifying aspects of the existing product in ways that inadvertently reduced the feasibility of the resulting design. This could be attributed to the fact that our participants were first-year engineering students with limited prior exposure to engineering concepts and domain-specific knowledge. As such, it is our recommendation that visual inspection activities be utilized as a method of fine-tuning early-phase conceptual ideas. Visually inspecting existing products could serve to improve the quality of the final design by exposing the designer working solutions to similar design problems, thereby increasing the overall feasibility of the final design.

Although our work provides insights into the impact of 3D designer-product interactions, more work is needed to examine and compare the impact of $2 \mathrm{D}$ and $3 \mathrm{D}$ models. This is important because it allows a baseline of comparison between prior studies in ideation and recent work on 3D models. In addition, because it is observed that different designer-product interactions are useful for different design goals, future studies should examine these interactions in more detail, focusing on their impact on design creativity. This work will contribute to our understanding of how to implement different design techniques and at what stage of the design process it is most effective in addressing the design goal.

\section{Supporting Novice Designers in Creative Thinking}

Since product dissection is widely implemented in the academic setting $[9,35,45,46]$, it can be utilized to encourage students to explore novel and original areas in the solution space, and to help educators teach creative thinking in engineering design. However, from our results, it was observed that the novice designers had difficulties generating feasible concepts while still being able to develop ideas in novel avenues. This finding is supported by prior studies that have shown that product dissection encourages the application of 
knowledge [45] and the focus on the more functional aspects of design [6]. Thus, novice designers may have been unable to draw on core engineering concepts because of a lack of knowledge in these areas. As such, support systems should be implemented in order to aid novice designers in developing practical concepts. With more exposure to the working principles of designs, creativity can be increased and design outcomes can be improved.

Future studies should explore the role of product dissection in engineering industry in more depth. This is critical in validating the research findings of studies done in academia, and can provide the design community with practical approaches to increasing design creativity. Understanding the various tools used in industry can also provide researchers with valuable insights for developing design support tools that can be utilized in naturally-occurring design environments. Efforts in making product dissection more accessible and practical through implementing virtual dissection tools and repositories is also important in encouraging dissection across various settings.

\section{Naturally Occurring Design Practices Influence Creativity at Varying Degrees}

In addition to understanding the impact of when to use dissection and visual inspection in design, our findings also highlight the importance of studying design practices commonly used in industry. Most of the work on example usage in design focuses on examining the effect of carefully selected formalized techniques on design creativity. This is problematic because it limits the implications and generalizability of the results with respect to practical engineering design settings. Therefore, the current study took an alternate approach at studying design creativity by studying the impact of two commonly utilized design techniques (visual inspection and product dissection). Our results indicate that these commonly used methods yield different design outcomes. Therefore, it is clear that different types of naturally occurring design practices can greatly affect the creativity of design outcomes.

While the current study adds to our understanding of designer-product interactions and its associated cognitive mechanisms as it occurs in practice, more research is needed to examine design practices in detail in order to add to our understanding of design creativity. This area of research is crucial to the study of engineering design because it can give us insights into methods of leveraging currently practiced design methods for increasing design creativity. In addition, research comparing creativity assessment methods should be conducted in order to explore ways of assessing creativity in other interdisciplinary and complex design contexts.

\section{CONCLUSION}

The current study was developed to understand the differences in the creativity of design outcomes between two types of designer-product interactions. Overall, the results from our study support our hypothesis that the type of designerproduct interaction impacts design creativity. This finding has important implications for the field of engineering design because it adds to our understanding of how existing design methods can be used to support design creativity.

This study contributes to the existing research on product dissection's utility in the engineering classroom $[21 ; 51 ; 22 ; 24$; $20]$ and in industry. In particular, this study highlights the benefit of interacting with products at a deeper level (dissection) in contrast to surface-level interactions with existing products for increasing design novelty. When designers are looking to focus their design ideas and produce higher quality solutions, visual inspection should be used as this surface level interaction allows designers to focus on particular facets of the design. Overall, the results of this study add to our understanding of how and when product-designer interactions can be used to aid in the idea generation process

\section{ACKNOWLEDGMENTS}

We would like to thank our undergraduate research assistants Arti Patel, Boyd Warwick-Clark, and Kristen Murray and our participants for their help in this project.

\section{REFERENCES}

1. Herring, S., et al. Getting Inspired! Understanding How and Why Examples are Used in Creative Design Practice. in CHI-Design Methods. 2009. Boston, MA.

2. $\quad$ Eckert, C., M. Stacey, and C. Earl. Reasoning by References to Past Design. in International Workshop on Studying Designers. 2005.

3. Lubart, T., How can computers be partners in the creative process: classification and commentary on the special issue. International Journal of HumanComputer Studies 2005. 63(4-5): p. 365-369.

4. Viswanathan, V. and J.S. Linsey, Physical Models in Idea Generation- Hindrance or Help?, in Design Engineering Technical Conferences2010: Montral, Quebec.

5. Toh, C., S. Miller, and G. Okudan Kremer, The Impact of Product Dissection Activities on the Novelty of Design Outcomes, in ASME 2012 International Design Engineering Technical Conferences \& Design Theory and Methodology2012: Chicago, IL.

6. Grantham, K., et al., A Study on Situated Cognition: Product Dissection's Effect on Redesign Activities, in International Design Engineering2010: Montreal, Quebec, Canada.

7. Bonnardel, N., Towards understanding and supporting creativity in design: analogies in a constrained cognitive environment. Knowledge-Based Systems Journal, 2000. 13(7-8): p. 505-513.

8. Ulrich, K.T., S.D. Eppinger, and A. Goyal, Product design and development. Vol. 2. 2011: McGraw-Hill.

9. Lamancusa, J. and J. Gardner. Product Dissection in Academia: Teaching Engineering the Way We 
Learned it. in International Conference on Engineering Education. 1999.

10. Brereton, M., The role of hardware in learning engineering fundamentals: An empirical study of engineering design and disection activity, in Mechanical Engineering1998, Stanford University: Palo Alto.

11. Toh, C., S. Miller, and G. Okudan Kremer, Mitigating Design Fixation Effects in Engineering Design Through Product Dissection Activities, in Design Computing and Cognition2012: College Station, TX.

12. Jansson, D. and S. Smith, Design Fixation. Design Studies, 1991. 12: p. 3-11.

13. Purcell, A. and J. Gero, Design and Other Types of Fixation. Design Studies, 1996. 17(4): p. 363-383.

14. Chrysikou, E. and W. Weisberg, Following the Wrong Footsteps: Fixation Effects of Pictorial Examples in a Design Problem-Solving Task. Journal of Experimental Psychology, 2005. 31(5): p. 1134-1148.

15. Linsey, J., et al., A Study of Design Fixation, Its Mitigation and Perception in Engineering Design Faculty. Journal of Mechanical Design, 2010. 132: p. 41003.

16. Dugosh, K., et al., Cognitive Stimulation in Brainstorming. Journal of Personality and Social Psychology, 2000. 79(5): p. 722-735.

17. Leggett Dugosh, K. and P.B. Paulus, Cognitive and social comparison processes in brainstorming. Journal of Experimental Psychology, 2005. 41: p. 313-320.

18. Brown, V.R. and P.B. Paulus, Making group brainstorming more effective: Recommendations from an associative memory perspective. Current Directions in Psychological Science, 2002. 11: p. 208-212.

19. Simpson, T. and H. Thevenot, Using Product Dissection to Integrate Product Family Design Research into the Classroom and Improve Students' Understanding of Platform Commonality. International Journal of Engineering Education, 2007. 23(1): p. 120-130.

20. Wood, K., et al., Reverse Engineering and Redesign: Courses to Incrementally and Systematically Teach Design. Journal of Engineering Education, 2001. 90(3): p. 363-374.

21. Altshuller, G.S., Creativity as an exact science: The theory of the solution of inventive problems. Vol. 320. 1984, Luxembourg: Gordon and Breach Science Publishers.

22. Eberle, B., Scamper: games for imagination development1996, Waco, TX: Prufrock Press.

23. Osborn, A., Applied Imagination1957, New York, NY: Scribner.

24. VanGrundy, A., Techniques of Structured Problem Solving. 2nd ed1988, New York, NY: Van Nostrand Reinhold Company.

25. Kulkarni, S., et al., Evaluation of collaborative (CSketch) as an idea generation technique for engineering design. Journal of Creative Behavior, 2000. 35(3): p. 168-198.

26. Gilbert, J.K. and R.J. Osborne, The use of models in science and science teaching. European Journal of Science Education, 1980. 2(1): p. 3-13.

27. Ingham, A. and J.K. Gilbert, The use of analog models by students of chemistry at higher education level. International Journal of Science Education, 1991. 13(2): p. 193-202.

28. Yakimanskaya, I.S., The development of spatial thinking in schoolchildren. Soviet Studies in Mathematics Education. Vol. 3. 1991, Reston: N.C.T.M.

29. Gutierrez, A., Visualization in 3-Dimensional Geometry: In Search of a Framework, in PME CONFERENCE1996.

30. McKoy, F.L., et al., Influence of design representation on effectiveneses of idea generation, in Design Engineering Technical Conferences2001: Pittsburgh, PA.

31. Viswanathan, V. and J.S. Linsey, Physical Examples in Engineering Idea Generation: an Experimental Investigation, in International Conference on Design Creativity2012.

32. Youmans, R., The Effects of Physical Prototyping and Group Work on the Reduction of Design Fixation. Design Studies, 2010.

33. Viswanathan, V.E., NE; Linsey, J, TrainingTomorrow's Designers: A Study On The Design Fixation, in ASEE Anual Conference 2012: San Antonio, TX.

34. Devendorf, E., et al., Using product archaeology to integrate global, exonomic, environmental and societal factors in introductory design education, in Design Engineering Technical Conferences2011: Washington, DC.

35. Wood, K.J., D; Bezdek, J; Otto, KN, Reverse Engineering and Redesign: Courses to Incrementally and Systematically Teach Design. Journal of Engineering Education, 2001. 90(3): p. 363-374.

36. Nelson BA, Y.J., Refined metrics for measuring ideation effectiveness. Design Studies, 2009. 30: p. 737-743.

37. Doyle, T.E., B.W. Baetz, and B. Lopes, First-year engineering bicycle dissection as an introduction to sustainable design, in Canadian Engineering Education Association 2011.

38. Shah, J. and N. Vargas-Hernandez, Metrics of Measuring Ideation Effectiveness. Design Studies, 2003. 24: p. 111-124.

39. Linsey, J.S., et al., An Experimental Study of Group Idea Generation Techniques: Understanding the Roles of Idea Representation and Viewing Methods. Journal of Mechanical Design, 2011. 133.

40. Srivathsavai, R., et al., Study of Existing Metrics Used in Measurement of Ideation Effectiveness, in ASME 
2010 International Design Engineering Technical Conferences \& Computers and Information Engineering Conference2010: Montreal, Quebec, Canadac.

41. Chrysikou, E.G. and R.W. Weisberg, Following in the wrong footsteps: Fixation effects of pictorial examples in a design problem-solving task. Journal of Experimental Psychology, 2005. 31(5): p. 113411448 .

42. Shah, J., S. Kulkarni, and N. Vargas-Hernandez, Evaluation of idea generation methods for conceptual design: effectiveness metrics and design of experiments. Journal of Mechanical Design, 2000. 122: p. 377-384.

43. Vargas-Hernandez, N.S., JJ; Smith, SM, Understanding Design Ideation Mechanisms Through
Multilevel Aligned Empirical Studies. Design Studies, 2010.

44. Kudrowitz, B.M. and D.R. Wallace, Assessing the quality of ideas from prolific, early-stage product ideation, in Design Engineering Technical Conferences2010: Quebec, Canada.

45. Odesma, O.S., DA; Evangelou, D, The Motivational and Transfer Potential of Disassenblel Analyzel Assemble Activities. Journal of Engineering Education, 2011. 100(4): p. 741-759.

46. Lamancusa, J., J. Jorgensen, and J. Fridley, Product dissection- A Tool For Benchmarking in the Process of Teaching Design, in Frontiers in Education Conference 1996: Salt Lake City, UT.

\section{APPENDIX}

\section{Visual Inspection Condition Instructions}




\section{Product Benchmarking of a Milk Frother}

Product Benchmarking is often used in both industry and academia to identify the strengths and weaknesses of a wide range of products. It is important in product design because it encourages designers to search for best practices, thus leading to superior performance of the product. Keep in mind that the provided milk frother only demonstrates one solution to the problem and there may be better methods of frothing milk. Your goal is to understand strengths and weaknesses of the product in order to develop new, innovative concepts for a product that satisfies the design goal.

Once again, the goal is to develop concepts for a new, innovative product that can froth milk in a short amount of time. This product should be able to be used by the consumer with minimal instruction.

During this activity, you will interact with the provided milk frother, sketch it, and benchmark its features.

\section{Task 1:}

Sketch the milk frother in the space provided on the next page. Include dimensions obtained from measuring the milk frother with the provided ruler. Include the front, top, and isometric perspectives of the milk frother in your sketches. An example sketch of an office chair with dimensions is shown in Figure 1.

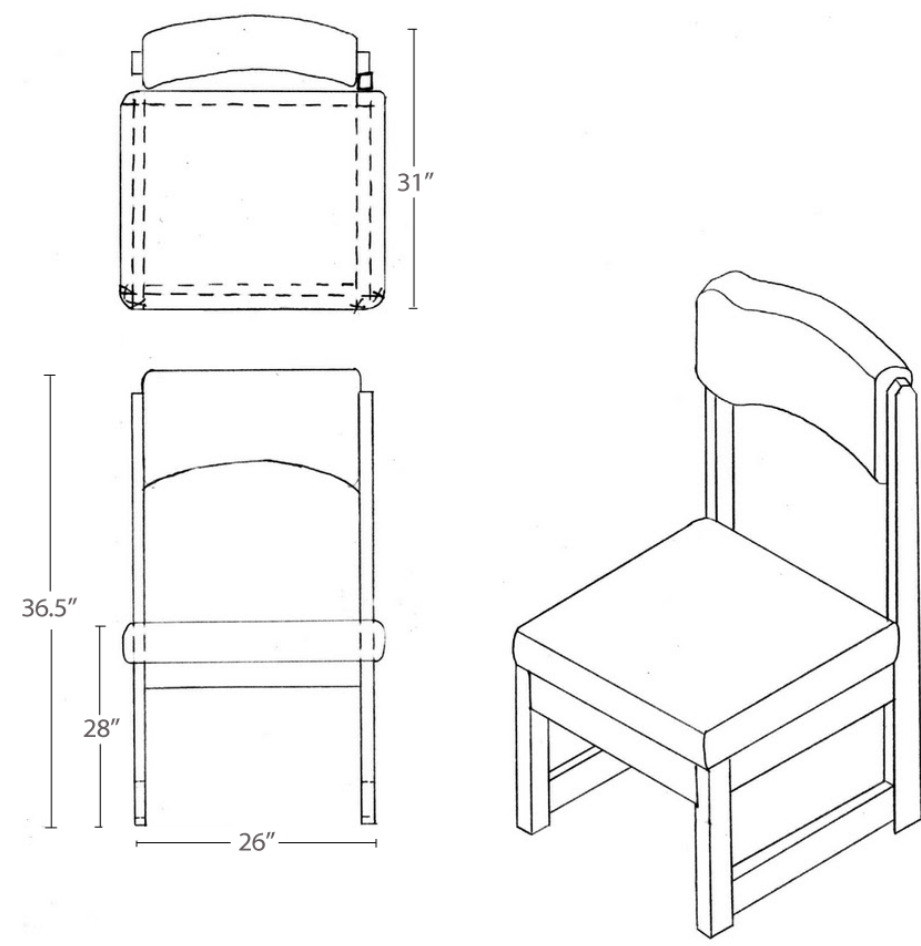

Figure 1: Examples of top, front, and isometric views of an office chair.

\section{Task 2:}

Four main aspects of the design that are important to the success of the product are provided in Table 1.

Use the space provided in Table 1 to generate a written description of your observations of the milk frother based on these 4 concepts. Include as much detail as time permits. 
Keep in mind the main goal of this re-design activity as stated in the problem description:

The main goal of your task is to develop concepts for a new, innovative product that can froth milk in a short amount of time. This product should be able to be used by the consumer with minimal instruction.

Table 1: Written description and opinion on the 4 design aspects of the milk frother.

\begin{tabular}{|l|l|}
\hline \multicolumn{1}{|c|}{ Aspects of the Milk Frother } & \\
\hline $\begin{array}{l}\text { Aesthetics: The appearance of the } \\
\text { product and the impression it } \\
\text { makes on potential customers. }\end{array}$ & \\
\hline $\begin{array}{l}\text { Functionality: The extent to which } \\
\text { the product satisfies its purpose for } \\
\text { which it was made. }\end{array}$ & \\
\hline $\begin{array}{l}\text { Durability: The impression of } \\
\text { sturdiness and quality of the } \\
\text { product. }\end{array}$ & \\
\hline $\begin{array}{l}\text { Ease of Use: The ease at which } \\
\text { users will be able to operate the } \\
\text { product, including aspects such as } \\
\text { comfort, and intuitiveness. }\end{array}$ & \\
\hline
\end{tabular}

\section{Product Dissection Condition Instructions}

\section{Product Dissection of a Milk Frother}


Product dissection is often done in industry and academia to uncover opportunities for re-design. Designers take apart and analyze all components of a product to understand its structure and properties, and thus, find ways to improve the product. Therefore, the goal of dissection is to improve the functionality, maintainability, and reliability of a product through the examination, study, capture, and modification of existing products.

During this activity, you will perform a product dissection on the provided milk frother by taking it apart, performing measurements and analyzing the function of each component in order to help in the re-design of the product. Keep in mind that the provided milk frother only demonstrates one solution to the problem and there may be better methods of frothing milk. Your goal is to understand strengths and weaknesses of the product in order to develop new innovative concepts that satisfy the design goal.

Once again, the goal is to develop concepts for a new, innovative product that can froth milk in a short amount of time. This product should be able to be used by the consumer with minimal instruction.

\section{Task 1:}

There are a total of 12 parts in the milk frother that you will dissect. The name of each part has been included in the Bill of Materials (BOM) in Table 1. Remember to take apart the product until it cannot be practically reduced to any more parts. In other words, do not worry about damaging the product during this activity- completely take apart your product. Your task is to disassemble the milk frother, identify each part, and record the following:

QTY: $\quad$ quantity of each part within the milk frother. Eg. If there were 4 batteries you would write 4 in this box.

SOP effect: Subtract and Operate Procedure. This helps us understand if the component is essential to the operation of the device and can be thought of as the answer to the following question:

"Does the product still function after this part has been removed?"

If the answer is yes, then fill in 'yes' in that column, and 'no' if the product will fail to function after that part has been removed. Eg. If you remove the batteries, the part will no longer function, making the battery's SOP effect a 'no'.

Material: $\quad$ the material the part is made from (if you do not know for sure, write your best estimate)

Dimensions: the rough measurements (in inches) of the part. Use this format: length $\mathrm{x}$ width $\mathrm{x}$ depth. If the part has a complex geometry, simply report the longest dimension along its length, width, and depth respectively. 